International Journal of English Literature and Social Sciences
Vol-6, Issue-2; Mar-Apr, 2021

\title{
Archetypal Criticism: A Brief study of the Discipline and the Sempiternal Relevance of its Pioneers
}

\author{
Divya Gijo ${ }^{1}$, Kevin George ${ }^{2}$
}

\author{
${ }^{1} 2^{\text {nd }}$ Year P.G Student, S.B College, Kottayam, India \\ ${ }^{2}$ Department of English Literature, K.E College, Mannanam, India
}

Received: 12 Dec 2020; Received in revised form: 11 Feb 2021; Accepted: 25 Feb 2021; Available online: 14 Mar 2021 (C)2021 The Author(s). Published by Infogain Publication. This is an open access article under the CC BY license (https://creativecommons.org/licenses/by/4.0/).

\begin{abstract}
Northrop Frye was a Canadian literary critic and theorist. He was born on 14th July,1912 in Sherbrooke in Quebec, Canada. Harold Bloom called him a "Miltonic figure" (qtd. By Bloom in an interview) of literary criticism for his exemplary and original contributions to the field of literary criticism. Frye was educated at the University of Toronto where he was a theology and philosophy major. He then did his postgraduate degree in English at Merton College, Oxford. In 1939 he returned to Canada and started teaching at Victoria College, University of Toronto where he spent the rest of his literary career. Northrop Frye is viewed as a pioneering critic of archetypal criticism. His first book The Fearful Symmetry: A Study of William Blake written in 1947 was a highly original study of Blake's poetry and is considered a seminal critical work. He shot to international fame with the publication of his book titled The Anatomy of Criticism: Four Essays written in 1957 "which redirected American literary theory away from the close reading of New Criticism and towards the larger meanings of literary genres, modes and archetypes." (Drabble 386). Regardless of the critical evaluation, he stressed on a value-free science of criticism. Frye in most of his works elaborate a comprehensive map of the literary universe in a schematic series of classifications. He has written over twenty books on various subjects including culture, myth, social thought and archetypal theory. His famous works include The Fables of Identity: Studies in Poetic Mythology, Secular Scripture, The Great Code: The Bible and Literature, Spiritus Mundi, The WellTempered Critic and Northrop Frye on Shakespeare. Frye was a polymath who had extensive knowledge on various subjects such as western culture, archetypal criticism, religion, anthropology et cetera. The Fables of Identity: Studies in Poetic Mythology, published in 1963 is the collection from which the essay "The Archetypes of Literature" is taken. It was originally published in The Kenyon Review in 1951. Frye analyses literature with respect to various rituals and myths. He drew inspiration from many sources including the Bible, Blake's prophetic books, Oswald Spengler, Sigmund Freud and James George Frazer. But the main source of influence was the Swiss psychologist Carl Jung. Frye was immensely influenced by his account of the collective unconscious. But ironically Frye objected to being called a Jungian critic because he said that the literary critics should be concerned only with the ritual or dream patterns and need not concern themselves with how the symbols actually got there.
\end{abstract}

Keywords-Archetye, The Collective Unconscious, Northrop Frye, C.G Jung, Freud.

\section{ARCHETYPES AND ARCHETYPAL CRITICISM}

The word archetype arises from two Greek words arche meaning beginning and type meaning imprint. William $\mathrm{K}$. Wimsatt and Cleanth Brooks say in Literary Criticism "archetype, borrowed from Jung, means a primordial ISSN: 2456-7620

https://dx.doi.org/10.22161/ijels.62.11 image, a part of the collective unconscious, the psychic residue of numberless experiences of the same kind, and thus part of the inherited response pattern of the race." (709). The inception of the archetypal hypothesis dates back to the ancient times of Plato. His eidos or ideas were mental forms imprinted in the soul before it arrived in this 
world. Eidos embodied the fundamental characteristics of a thing and not its particularities and hence they can be called collective. The main exponent of archetypal criticism is Carl Gustav Jung, who pioneered the concept of archetypes in his book The Spirit of Man, Art and Literature in 1922. He was a student of Freud and was the first critic and philosopher to give prominence to the term archetype. He introduced the theory of the "collective unconscious" or racial memory by which he meant that in the unconscious there are images or patterns that are not derived from personal experience but are inborn. The unconscious aids the individuals to maintain a balanced psychological state. He says that archetypes are the contents of the collective unconscious that can be found across cultures. Archetypes are symbols, characters and motifs that stir a primary feeling in the mind of humans everywhere.

Archetypal critics argue a universality in literature by pointing to a recurring pattern embedded in the cultural psyche. It is built on the belief that every work of literature can be categorised and fitted into a larger framework that encompasses all literature. Archetypes are the clues to finding wholeness. An image, symbol or motif should recur throughout literary history for it to be approved as an archetype. An archetype is an original template from which copies are made.

\section{JUNGIAN ARCHETYPES}

Jung described archetypes as patterns of psychic energy originating in the collective unconscious and finding the most common and most normal manifestation in dreams. He delineates four archetypes of man that are Persona, Self, Shadow and Anima/Animus. Persona traces its etymological roots to a Latin word that means 'mask'. It is how we present ourselves to the world. The Self represents the unified unconsciousness and consciousness of an individual. Jung represented Self as a circle or mandala. Shadow is the archetype of primal instincts including sexual desire and life instincts. It exists as a part of the unconscious mind and are composed of repressed ideas, weaknesses, desires and shortcomings. Anima is the feminine image in the male psyche and Animus, the male image in the female psyche. They represent our true self. Hence anima is the female aspect in men and animus the male aspect in women and its combination is known as syzygy or the divine couple.

\section{JUNG'S UNIVERSAL CHARACTER ARCHETYPES}

He further identified twelve universal, mythical character archetypes that inhabit our collective unconscious. They are Ruler, Creator, Sage, Innocent, Explorer, Rebel, Hero, Wizard, Jester, Everyman, Lover and Caregiver. These are further categorized into three types-the ego types, the soul types and the self-types.

\section{ARCHETYPAL SITUATIONS, SUBJECTS AND IMAGES}

These are the situations, subjects and images that are recurrent throughout the cultures. Archetypal situations include rivalry between brothers, the longing for a father figure, country bumpkin coming to the city for the first time, the tension between different generations. Archetypal subjects include birth, love, war, guilt, redemption, death. Archetypal images include lion, eagle, ox, serpent, dove.

The first systematic application of Jungian ideas to literature was made in 1934 by Maud Bodkin in Archetypal Patterns in Poetry. James George Frazer, an anthropologist in his book The Golden Bough makes a detailed study of magic, myth and religion of different races. Christopher De Quincy, the philosopher and anthropologist suggested that archetypes are ancestral cyclic patterns shared across culture as countless forms buried deep in our collective unconscious. Frye strays from the Jungian theory and insisted on a Lamarckian view of genetic transformation of archetypes which Jung explicitly rejected. Joseph Campbell, the famous twentieth-century theorist in his seminal text The Hero with a Thousand Faces (1949) introduces the concept of monomyth. It refers to the theory that views all mythical narratives as variations of a single great story. He lists eight-character archetypes found throughout a hero's journey and these are Hero, Mentor, Ally, Herald, Trickster, Shapeshifter, Guardian and Shadow.

\section{SUMMARY OF THE ESSAY}

Northrop Frye's famous essay "The Archetypes of Literature" is divided into three parts. In the first part Frye elucidates what an archetype is. In the second part of the essay he talks about the inductive study of works concerning archetypal criticism and in the third part he talks about deductive analysis. Frye in the beginning of his essay distinguishes between two types of criticism: meaningful criticism and meaningless criticism. Meaningless criticism doesn't help the systematic structure of knowledge about a work of literature.

Frye puts forward the statement that it is impossible to learn literature. It has to be felt and savoured. What one learns actually is the criticism of literature which is the 
only thing that can be taught. He asks why criticism cannot be viewed, at least, partly as a science. He says that just because it is part of art doesn't mean that it cannot have an organised system. Frye again gives momentum to his arguments by saying that many areas in literature are, in fact, scientific like prosody, phonetics, philology and other activities such as editing the text investigating the source and so on. He says so because they adhere to a set of patterns. Literature is the central division of Humanities. He says that literature borrows both from history and philosophy. Criticism holds only a sub-position. Hence to get a systematic understanding of literature, a student of the subjects turns to his historians for information about events and philosophers for ideas. "In defining genuine criticism Frye shows how it is connected to but different from philosophy, theology, history and social sciences, meriting autonomy as a rigorous and comprehensive professional university discipline." (Leitch 1444). Northrop Frye makes an interesting statement concluding the second paragraph of the essay. He says, "criticism would be to art what philosophy is to wisdom and history to action."

Criticism majorly deals with a sort of commentary. Frye says that unlike scientific researchers the critics engage in a sort of over-glorified verbosity that has no tangible meaning. If we attempt to get an understanding of criticism we will be thwarted by unstable generalities, abstract comments on the value and highly rhetorical statements. He criticizes this hollow nature of criticism by suggesting that they are pseudo- propositions which are statements that seem meaningful at first glance but turn out to be meaningless once they are philosophically analysed. Hence this is the first argument that Frye puts forward in the essay where he makes a distinction between meaningful and meaningless criticism. He rejected critical evaluation in favour of a value-free literary science. He dismisses value-judgments as they mostly reflect the sociological and psychological influences that made the person say it. He observed that the thing missing from the current criticism was a central hypothesis or a principle to co-ordinate everything that lay in a disarray.

Frye uses the terms centripetal and centrifugal to describe the different critical methods. Criticism is centripetal when it moves inward and towards the structure of the text and it is centrifugal when criticism moves outward from the text to the outer world. When you study only in an analytical sense a centrifugal force carries you away from the centre which is indubitably literature itself. He then describes and differentiates between structural and historical criticisms. The Formalist Critics go centripetal where they delve deep into the structural pattern of the text. According to them, literature is a closed coherent system that prevents the infiltration of external elements. They say that to keep the study of the structure of a literary work one needs to learn the complexities and should expel any external factors that do not aid the immediate comprehension of the text. Although he admits the merits of structural analysis, he also envisages its shortcomings. This method is an anti-thesis of background study for criticism. Frye is an extraordinary synthesizer. He resolves this conflict by finding a meeting point between the opposing criticisms. Archetypal criticism is the synthesis of structural criticism and historical criticism.

Frye calls criticism a science. He dismisses the belief that a critic need not concern himself with finding out more than the meaning given by the poet in the poem. He shuns this belief as a fallacy. He states that it takes time for an individual discipline to identify itself as "a totally intelligible body of knowledge" and this is common in every form of sciences. Frye says that a combination of inductive and deductive analysis is necessary for the right manner of criticism.

In archetypal criticism, the critic holds the centre stage. He says that the critic takes over from where the poet left off. Every poet has his own private mythology of symbols and images which he is oblivious of. He showed how these symbols covertly take their places in the works of certain authors. Frye enquires about the origin of the genre and observes that the social conditions and cultural demand produced the work of art in that genre. The social and cultural milieu is responsible for the birth of a text. Hence historic inductive method helps the reader in understanding not only symbols, images and myth but also the very genre itself. Literary historians find images, symbols and motifs in texts across history and conclude that they have a common origin. He gives the example of W. H. Auden's work Enchaféd Flood where he examines the images of the sea. The symbols of the sea are not confined to the poems of Keats, Shelley or Coleridge but emerge as a much bigger symbol of literature. Frye synthesized structural criticism and historical criticism and formed a new type of literary criticism known as archetypal criticism. He asserts that archetypal criticism is a meaningful criticism. Archetypal criticism interprets a text concerning the cultural patterns involved in it and these cultural patterns are based on myth, rituals, race, nation or social group. He gives the example of the gravedigging scene of Hamlet in Act 5 Scene 1. For the archetypal critic, this scene is inlaid with rich references. In order to decode the intricate layers of meaning, the critic travels back to the works of J.Wilson Knight and Caroline Spurgeon who called to attention Shakespeare's patterns of imagery and symbolism. He then takes a step back to analyze A.C. Bradley's commentary on the psychological 
study of the characters. A step back more to Shaw and E. E. Stoll who focused on the relationship of Shakespeare's play to the dramatic conventions of the Elizabethan and Jacobean age and finally to the Liebestod which is a German term meaning 'death of love' specifically an operatic aria or duet on the suicide of lovers or more generally the thematic linking of love and death. Therefore, Frye proposes that the story of Hamlet has its origins in a primitive nature myth.

Frye proposes a series of literary interventions from the critics in a prescribed order. He considers archetypal criticism as an all-inclusive term. He seeks help from scholars belonging to various fields of expertise. This includes utilizing methods of many specialist at every stage of interpretation. The editor has the duty to clean up the text for detailed study and analysis, the rhetorician examines the narrative of the text, the philologist scrutinizes the choice and significance of the words and the literary social historian studies the evolution of myth and ritual in society. Then the literary psychologist will shed light on the psychological and psychoanalytical readings inside the text and detailed study of the genre. The literary historian needs to be consulted for the study of the archetype the literary anthropology. He traces the sources of Shakespeare's Hamlet to the Hamlet legend described by Saxo Grammaticus in the 13th-century Danish history in his book titled Danes Gesta Danorum and from there he further traces its source back to the nature myths which were prevalent during the Norman conquest period.

In the third part of the essay, Northrop Frye talks about the deductive analysis where the meaning of the work simmers down from the general truth to the particular truth. He says that some arts move in time and the recurrence is the central principle. He makes a distinction between the temporal and spatial art. the temporal is for music and spatial is the pattern. The organising principle is a recurrence or pattern. In temporal, there is a rhythm that repeats and in spatial, a pattern that repeats. He opines that literature is an intermediate between music and painting. Frye believed that the origin of a narrative is from human rituals and there are unconscious repetitions and patterns. In nature certain activities of animals like the mating dance of birds are ritualistic. But in the human world rituals are more of a voluntary effort. All the important recurrences such as day, the phases of moon, seasons etc. have rituals attached to them. Unlike rituals, the patterns of imagery are epiphanic or oracular. While these epiphanies manifest into proverbs, riddles, commandments and etiological folktales they already possess a considerable amount of narrative in them. Frye juxtaposes rituals and patterns and says that both are important and are the two integral parts of the myth formation. Myth is a pivotal informing power that gives archetypal significance to rituals and archetypal narrative to the oracular. Myth is archetype and vice versa, but we use the term myth relating to narrative and archetype when we speak about significance. writers use the patterns in their work consciously or unconsciously and it falls upon the critic to detect these archetypes and to explicate the patterns in the work.

Frye takes three similar cycles in nature which are the Solar cycle, the seasonal cycle of the year and organic significance of human life and pinpoints a single pattern of significance from which a myth constructs a central narrative. Mythos is the Greek word for 'plot 'or 'story'. Myth forms its narrative around a figure who is partly the sun, partly vegetative fertility and partly a god or archetype of the human being. Frye has tremendously borrowed from the works of Frazer and Carl Jung. Their works on archetypes and myths have usually influenced Frye and it is evident in his essay. Frye then proceeds to make a classification of the archetypes. He formulates four phases of Myth.

\section{THE PHASES OF MYTH}

The first one is the dawn, spring and birth phase. Myths surrounding the birth of a hero, his revival and resurrection, of creation and the defeat of the power of darkness, winter and death. The subordinate characters are the father and mother. This archetype is characteristic of dithyrambic poetry which was an ancient Greek tradition of poetry dedicated to the Greek God of fertility and wine, Dionysus. Here Frye uses the term comedy in the traditional meaning of the word. He means that the hero starts at a low point and ascends to a higher position as the story progresses.

The second is the zenith, summer, marriage or triumph phase. This constitutes the myths of apotheosis- the elevation of someone to a divine status, of sacred marriage and entering into Paradise. The subordinate characters here are that of the companion and the bride. This is the archetype of romance. Romance is correlated with summer because in this mythos the hero goes on minor adventures and falls in love. Romance is correlated to summer because summer shows the culmination of life in the seasonal calendar. Romance always culminates with some sort of triumph, usually in the form of marriage.

The third one is the sunset, autumn and death phase. The myth of fall, of the death of God, of violent death and sacrifice and of isolation of the hero. Subordinate characters are the traitor and the siren. He does not use the word tragedy to denote sadness. In such a narrative the main character descends from his initial point. Also, from 
the bright state of summer, it has reached a point of degeneration and decay. Autumn is the dying stage of the seasonal calendar and it parallels the 'fall' of the protagonist.

The fourth one is the darkness, winter and the dissolution phase. The myth of triumph of the dark powers like the floods and the return of chaos, of the defeat of Hero and Gotterdammerung which means "twilight of the Gods" in German. It shows a collapse of a society or dream marked by catastrophic violence. The subordinate characters are the ogre and the witch. This is the archetype of satire and irony. It is called ironic because in winter everything is in a state of frigid dormancy. Everything appears stagnant and lifeless. But that is not a permanent condition. Like Shelley said, "If winter comes can spring be far behind?" Winter is followed by spring which will bring out the world from its state of inertia and it will once again blossom and start to bustle with activity.

The seasons are associated with native parallels also

$\begin{array}{ll}\text { - } & \text { Summer-comedy. } \\ \text { - } & \text { Spring- romance } \\ \text { - } & \text { Autumn- satire } \\ & \text { Winter- tragedy }\end{array}$

Frye's analogy of the cycle of mythoi asserts how human lives and their expressions draws influence from the processes of the natural world. Nature is the mother of metaphor and story. Therefore, comedy, romance, satire and tragedy are the four classifications of myth that Frye identifies, and these four myths combined to form the quest of the hero or the quest myth.

\section{THE QUEST MYTH}

In most religions, there is a central quest by the heroes which becomes the narrative structure of the religious scriptures. Among the Christians, the quest-myth is that of a Messiah who goes on a quest for the Holy Grail. The literary critic then takes the sacred religious scriptures as the primary documents that have to be studied to obtain a comprehensive view of the archetypes and the recurring patterns. The critic makes a study of the genres and he zooms in to elucidate a text in terms of a myth. This type of criticism is called the inductive method of analysis were the critic moves from the general truth that is a myth, to the elucidation of the particular truth in a text. Frye calls the Quest Myth the original starting point of all the genres, Hence the inception of all the literary genres lies in the ancient narrative of quest myth. Northrop Frye proceeds to talk about the two authorities of archetypal criticism who influenced him hugely. The first one is Carl Jung and his concept of a collective unconscious or racial memory. Jung came up with the theory of collective unconscious' which meant that a civilized man unconsciously preserves the ideas and values of life followed by his ancestors and these are expressed unconsciously in the societies. Frye cites the example of Ruth Benedict's book Patterns of Culture in which he distinguishes between the Apollonian and Dionysian cultures, named after the Greek gods Apollo and Dionysus. The Dionysian cultures are ostentatious and flamboyant while the Apollonian cultures have value, restraint and modesty. Schiller, the famous German classicist makes a distinction in his work On Naïve and Sentimental Poetry between naïve and complex poetry. He views Greek poetry as primitive and original while sentimental poetry of the current age is sophisticated, complex and derivate. But they hark back to the naïve(period).

Frye attempts to find out the similarity between religion and literary criticism. In criticism, the hero is treated as a remnant of human. As far as the critic is concerned, God is a character in a human story like in the case of John Milton's Paradise Lost and the Bible. Criticism concerns itself only with the conceivable and not the explainable which is the same case with religion. The epiphanies that laid the foundation of criticism and religion cannot be theorized into tangible facts for they originate from the subconscious, from the dreams. It is internally a cycle of waking and dreaming which corresponds to the natural cycle of light and darkness. The daytime is when the man feels fear and frustration and the nighttime when his libido or forces life is activated. Frye wonders whether the correspondence between these two antithetical factors the original source of all imaginative life is. The correspondence between the antithesis is where art begins. Plato said that "art is a dream for awakened minds". Therefore, the communion of these antithetical forces makes a man able to perceive truth both in religion and literary criticism.

In myth god or hero is important because these characters who are portrayed like humans have superhuman powers over nature and this overtime gave rise to the vision of an omnipotent personality. The hero in the myth enters a world of apotheosis that is he is elevated to the status of God. In the world of apotheosis, hero moves away from the moving cycle of quest myth where triumph is temporary.

Frye elucidated the central archetypal images. The vision of innocence in the human world correspond to the unfallen world of heaven in religion and this vision may be called the comical vision of life. The tragic vision sees the quest only in the form of its ordained cycle. Frye gives us a table of contents where he attempts to decode the central 
pattern of the comic and tragic visions. The context of a genre determines how an image or symbol is interpreted. Frye outlines five different spheres in his schema namely, human, animal, vegetation, mineral and water.

\section{THE COMIC VISION AND THE TRAGIC VISION}

The comic vision of the human world is a community. The hero is a representative of the desires of a reader. Here the archetypes of images are symposium, communion, order, friendship and love. Marriage or and equivalent communion takes place in the comic version of the life. In the tragic vision of the human world, there is tyranny, anarchy, isolated man, leader backstabbing the followers, bullying giant of romance, deserted or betrayed hero. In addition to this, there will be a harlot, witch or various versions of a terrible mother. The human pattern is followed by divine entities and heroic and superhuman characters.

In the schema of the animal world, the comic vision of the world is presented as a community of domesticated animals usually a flock of sheep or lamb and gentle birds like the dove. the archetypes of pastoral images are prevalent. In the tragic vision, the animal world is infested by beastly creatures, birds of prey, wolves, vultures, dragons, serpent and other monsters.

In the vegetable world of comic vision, the images of garden, grove, park, a tree of life, rose or lotus recur. These are the archetypes of Arcadian images like Marvell's green world, of Shakespeare's forest comedies. The tragic vision of the world includes images such as a sinister forest like the one in Comus of Milton or the forest at the opening of Dante's Inferno, wilderness, tree of death.

In the schema of the mineral world, the comic vision of life includes images such as a city, or a building or temple or a stone presented as a glowing precious stone. The whole comic series especially the tree is conceived as fiery. archetypes of geometrical images such as starlit dome are also present. In the tragic vision of life, the mineral world of myth is seen as rocks, ruins, a geometrical image like the cross.

In the comic vision of life in the unformed world, there is a river, usually fourfold which influenced the Renaissance ideal of the four humours. In the tragic vision, the world gets transformed into the sea, the images are of dissolution and the myths of a flood. The amalgamation of sea and beast images give us leviathan like monsters. Frye takes W. B. Yeats's Sailing to Byzantium as a perfect example for the comic vision of life presented by the city, the tree, the bird, the community of sages, geometrical gyre and the detachment from the cyclic world. Romance, tragedy, irony and comedy are the four aspects of essential unified myth or quest myth.

\section{MERITS AND DEMERITS}

The advantages of archetypal criticism are that it studies an individual work as a part of the whole web of literature. This form of criticism liberates it from the bondage and determinism of social history and frames a new literary history. Hence, archetypal criticism makes literary criticism more scientific by giving laws that govern literature.

The main disadvantage of archetypal criticism is reductionism which means that this type of criticism reduces the whole of literature to a mono myth that is a quest myth. Another disadvantage of this lies in the fact that there is arbitrariness in the use of taxonomy and categorisation of literary works. The excessive emphasis laid on uniformity may lead to the dismissal of the uniqueness and the artistic integrity of a particular work. Another shortcoming of archetypal criticism is that it gives too much emphasis on the crude and unverifiable myth hunting. It may focus more on finding a ubiquitous universal pattern in the text rather than appreciating its unique elements. In the postmodern era where the lines between genres have blurred, Frye's schema becomes redundant or insignificant. Archetypes constantly need to be updated to accommodate the changes of times. In postmodern literature, there is a considerable increase of experimental works and innovating narration. These works may be an amalgamation of two or more genres and hence cannot be categorized into just any one of Frye's mythoi. Waiting for Godot by Samuel Beckett is such a work. It blends elements of tragedy and comedy and is a tragicomedy. Due to the influx of critical perspectives, archetypal criticism and Frye's influence diminished in the latter half of the twentieth century.

\section{CRITIQUE OF NORTHROP FRYE AND HIS THEORY}

Frye and his concepts are considered obsolete by modern critics. Terry Eagleton is said to have remarked in a debate "Who reads Frye now?" William Kerrigan remarked that during his heyday Frye has exercised the literary canon like no other. But now his popularity has considerably waned and "The feminists, post-modernists, newhistorians and neo-Marxists have buried him in a grave marked as White Male Liberal Humanist." (198). Many postmodern critics disparaged his attack on subjectivity, 
individuation, and the romantic concept of the self. Frye's notion of centre of the order of words crucially rejects Derrida's notion that such metaphors of centre, origin and structure close off possibilities of 'free play'. Frye vehemently dismissed deconstruction and in one of his diary entries, he writes that as a critic he has taken upon himself the task of reversing the deconstruction process that will lead to the extinction of literature and criticism. He calls deconstruction 'suicidal and destructive'. Richard Lane comments that Frye is not in vogue anymore. He says that Frye "attempts to account for the entire field of literary criticism in a totalizing gesture that is now read as deluded." (112). Unfortunately, Northrop Frye and his brand of archetypal criticism do not hold much sway over the literary scene. A shame, no doubt.

\section{REFERENCES}

[1] Abrams, M. H. "Archetypal Criticisms." A Glossary of Literary Terms.11th ed., Cengage Learning, 2015, pp 18-19.

[2] Drabble, Margaret. The Oxford Companion to English Literature, edited by Margaret Drabble. 6th ed., Oxford University Press, 2000

[3] Frye, N. (1951). The archetypes of literature. The Kenyon Review, 13(1), 92-110.

[4] Leitch, Vincent B. "Northrop Frye." The Norton Anthology: Theory and Criticism, edited by Vincent. B. Leitch. Norton, 2001, pp 38, 386. 